\title{
Sirolimus in Infants with Multiple Cardiac Rhabdomyomas Associated with Tuberous Sclerosis Complex
}

\author{
Maurizio Lucchesi ${ }^{a} \quad$ Enrico Chiappa ${ }^{b}$ Flavio Giordano ${ }^{c}$ Francesco Maric $^{c}$ \\ Lorenzo Genitori ${ }^{\mathrm{c}}$ lacopo Sardi ${ }^{\mathrm{a}}$
}

aNeuro-Oncology Unit, Department of Pediatric Oncology, Meyer Children's University Hospital, Florence, Italy; ${ }^{b}$ Pediatric Cardiology Unit, Department of Pediatric Medicine, Meyer Children's University Hospital, Florence, Italy; ' $D e p a r t m e n t$ of Neuroscience, Meyer Children's University Hospital, Florence, Italy

\section{Keywords}

mTOR inhibitors - Sirolimus - Tuberous sclerosis complex · Cardiac rhabdomyomas .

Subpendymal giant cell astrocytomas

\begin{abstract}
Introduction: Cardiac rhabdomyomas represent a frequent manifestation of tuberous sclerosis. Tumor growth, mainly prenatally, can result in intrauterine fetal or neonatal deaths in almost $10 \%$ of patients. Case Report: We treated 3 consecutive infants aged less than 12 months with sirolimus, an oral mTOR inhibitor. All patients achieved significant reductions in cardiac rhabdomyomas. A complete response was documented in 2 patients, while a partial response with tumor debulking greater than $50 \%$ was seen in the other one. The median time to best cardiac response was 1.9 months in all patients, and 3.3 months in those with complete response. The side effects profile was acceptable. Conclusion: Sirolimus may have a significant role in promoting natural regression of cardiac rhabdomyomas. Prospective clinical trials are needed.




\section{Case Reports in Oncology}

\section{Introduction}

Tuberous sclerosis complex (TSC) is a rare autosomal dominant syndrome, with variable penetration, characterized by the presence of benign, noninvasive, tumor-like lesions (hamartomas) in the brain, heart, skin, kidney, lung, and liver [1].

Around $60 \%$ of children with TSC have been reported to have cardiac rhabdomyomas (CRs) [2]. It is known that CRs may regress spontaneously, although the regression mechanism is not yet well understood. Partial regression of the CRs has been reported in $50 \%$ of cases and complete resolution in 18\% [3]. CRs have the potential for severe cardiac complications, usually observed in fetal life or the early neonatal period. Complications can be due to obstruction of the intracavitary space and/or valvar orifices, involvement of the conduction system, with first through third atrioventricular block, or generating the substrate for atrial or ventricular tachycardia. These complications can cause low cardiac output, congestive heart failure, and even sudden death. The mortality rate of cardiac complications is $9.5 \%$ [4].

The central nervous system manifestations of TSC include subependymal giant cell astrocytomas (SEGAs), epilepsy, intellectual disability, and autism [5]. In some cases, SEGAs require resection, particularly if they cause obstructive hydrocephalus [6]. However, if not completely resected, SEGAs have a propensity to grow back.

Recently, oral mammalian target of rapamycin (mTOR) inhibitors demonstrated an activity in patients with TSC, in terms of reduction of SEGAs volume and improved control of seizures in patients with intractable epilepsy [7-10]. Currently, there are no clinical studies in infants (0-36 months), and in particular in those aged less than 12 months. Moreover, some case reports suggest a hypothetical activity in CRs [11-14]. The aim of our study was to evaluate the safety and the activity of daily sirolimus treatment on CRs and SEGAs in a series of infants aged less than 12 months with TSC.

\section{Case Presentation}

This is an open-label consecutive case series of patients conducted through our academic medical center (Meyer Children's Hospital). Participants included infants, aged 0-12 months, with diagnosis of TSC according to international criteria [15]. Patients with TSC should have diagnosis of multiple SEGAs and multiple CRs to evaluate the activity of sirolimus on these tumors. Diagnosis of these findings should be made, respectively, by a Gd-enhanced magnetic resonance (MR) scan and by transthoracic echocardiogram. In order to be included in the analysis, patients should have completed at least 6 months of therapy.

Sirolimus, available as oral suspension, was administered with a weight-adapted initial dose derived from the conventional dose of $1 \mathrm{mg} / \mathrm{m}^{2}$ once a day (using equivalence: $1 \mathrm{~m}^{2}=30$ $\mathrm{kg}$ ). The serum level of the drug was monitored every 4 weeks (accepted therapeutic range: 4-10 ng/L). Patients with a serum level outside the range were subjected to dose adjustment. For each patient, the treatment was approved by the local ethics committee. Informed consent was obtained from the parents or legal guardians in all cases.

Toxicity evaluation was performed according to the Common Terminology Criteria for Adverse Events (CTCAE) version 3.0. Response of SEGAs to therapy was evaluated according to the Response Evaluation Criteria in Solid Tumors (RECIST) version 1.1. 
As to CRs, we considered the best cardiac response (BCR) to therapy, which is the best response obtained in the various echo assessments on target lesions. Patients were classified into 4 different types of response (on the basis of comparison between the sum of the largest diameters of target lesions): (1) stable disease; (2) partial response, with tumor shrinkage less than $50 \%$ of the baseline; (3) partial response with tumor shrinkage more than $50 \%$ of the baseline; and (4) complete regression. Furthermore, the median time to BCR was evaluated.

The study group consisted of 3 male consecutive infants (aged 0-12 months), admitted to our hospital from September 2014 to March 2015. The mean age at the beginning of treatment was 7 months (range 1-11 months). TSC2 mutations were detected in 2 patients. Genetic assessment was not available in the other patient. Table 1 summarizes the clinical features of the TSC for each patient.

All patients received prenatal ultrasound diagnosis of CRs. In 1 patient, CRs were associated with cardiac complications such as paroxysmal supraventricular tachycardia that required $\beta$-blocker prophylaxis.

All patients had a diagnosis of SEGAs by an MR scan before the first month of life. Refractory focal epilepsy was present in 2 cases. In 1 case infantile spasms were also present. Epilepsy was treated with carbamazepine or carbamazepine-based regimens. Moreover, overcentimetric lesions and localizations at risk of hydrocephalus were present in cases 1 and 2, respectively.

All patients showed good tolerance to sirolimus. In particular, the most frequent toxicity was fever, without evidences of infection, which occurred in 2 patients, followed by constipation and hypercholesterolemia in 1 patient each. According to CTCAE version 3.0, all side effects were grade 1, except for fever (grade 2). As regards the serological level of sirolimus, 15 controls were performed. Dose adjustment was necessary a median of 2 times for each patient. No significant overdose was documented.

All children underwent at least 2 echocardiograms. BCR on CRs was complete response in 2 patients (Fig. 1) and partial response in the other one; in this case the tumor shrinkage was more than $50 \%$ of the baseline (Fig. 2). The median time to BCR in all patients was 1.9 months (range 0.8-4.7 months). In those with complete response, the median time to BCR was 3.3 months. There were no arrhythmic or obstructive cardiac complications in all patients during the follow-up.

All patients underwent at least one control of SEGAs with MR scan. The best response on SEGAs was stable disease in all patients, without dimensional/numerical progression or tumor shrinkage. However, there was an improvement in seizure control in all convulsant patients.

\section{Discussion}

Cardiac involvement in TSC is often predominant in the fetal period and first years of life with spontaneous involution in subsequent years. In our series we observed a substantial efficacy of sirolimus on CRs. All patients were affected by multiple and large-sized CRs. In one case, these tumors were associated with arrhythmic complications. Despite important cardiac involvement, after sirolimus therapy, we saw 2 complete responses and 1 partial response (with tumor debulking of more than 50\%). The median time to BCR was 1.9 months (range 
0.8-4.7 months). Moreover, in those who achieved a complete response the median time to BCR was 3.3 months. This time span seems to be too short to be due to natural spontaneous regression of CRs.

Sirolimus may have a role in promoting natural regression of CRs. This activity of the drug may be crucial in neonates or infants with CRs and cardiac complications. In fact, a more rapid reduction of the tumor volume could improve prognosis, allowing better control in life-threatening arrhythmias or relieving severe intracardiac obstructions, thus avoiding the need for surgical resection. Single case reports and short series have been published on the use of mTOR inhibitors in infants with similar features [11-14].

Also in our series, 1 patient experienced improvement in seizure control, with a complete response. SEGA size remained stable in all patients. Benefits on SEGAs have already been demonstrated with everolimus in over 100 pediatric and adult patients (age of patients was generally over 3 years and up to 34 years) $[10,11]$ and with sirolimus in a series of children older than 36 months [7].

Given recent suggestions, prospective clinical trials are needed, in particular to evaluate cardiac activity in newborns and infant patients.

\section{Statement of Ethics}

The authors have no ethical conflicts to disclose.

\section{Disclosure Statement}

All authors declare that there is no conflict of interest regarding the publication of this paper.

\section{References}

1 Curatolo P, Bombardieri R, Jozwiak S. Tuberous sclerosis. Lancet. 2008 Aug;372(9639):657-68.

2 Watson GH. Cardiac rhabdomyomas in tuberous sclerosis. Ann NY Acad Sci. 1991;615:50-7.

3 Jóźwiak S, Kotulska K, Kasprzyk-Obara J, Domańska-Pakieła D, Tomyn-Drabik M, Roberts P, et al. Clinical and genotype studies of cardiac tumors in 154 patients with tuberous sclerosis complex. Pediatrics. 2006 Oct;118(4):e1146-51.

4 Erdmenger Orellana J, Vázquez C, Ortega Maldonado J. Echocardiography in diagnosis of primary cardiac tumors in pediatrics (in Spanish). Arch Cardiol Mex. 2005 Apr-Jun;75(2):154-8.

5 Holmes GL, Stafstrom CE; Tuberous Sclerosis Study Group. Tuberous sclerosis complex and epilepsy: recent developments and future challenges. Epilepsia. 2007 Apr;48(4):617-30.

6 Byard RW, Blumbergs PC, James RA. Mechanisms of unexpected death in tuberous sclerosis. J Forensic Sci. 2003 Jan;48(1):172-6.

7 Krueger DA, Care MM, Holland K, Agricola K, Tudor C, Mangeshkar P, et al. Everolimus for subependymal giant-cell astrocytomas in tuberous sclerosis. N Engl J Med. 2010 Nov;363(19):1801-11.

8 Krueger DA, Care MM, Agricola K, Tudor C, Mays M, Franz DN. Everolimus long-term safety and efficacy in subependymal giant cell astrocytoma. Neurology. 2013 Feb;80(6):574-80.

9 Cardamone M, Flanagan D, Mowat D, Kennedy SE, Chopra M, Lawson JA. Mammalian target of rapamycin inhibitors for intractable epilepsy and subependymal giant cell astrocytomas in tuberous sclerosis complex. J Pediatr. 2014 May;164(5):1195-200. 


\section{Case Reports in Oncology}

\begin{tabular}{l|l}
\hline Case Rep Oncol 2018;11:425-430 \\
\hline DOI: 10.1159/000490662 & $\begin{array}{l}\text { (c) } 2018 \text { The Author(s). Published by S. Karger AG, Basel } \\
\text { www.karger.com/cro }\end{array}$
\end{tabular}

Lucchesi et al.: Sirolimus in Infants with Multiple CRs Associated with TSC

10 Franz DN, Belousova E, Sparagana S, Bebin EM, Frost M, Kuperman R, et al. Everolimus for subependymal giant cell astrocytoma in patients with tuberous sclerosis complex: 2-year open-label extension of the randomised EXIST-1 study. Lancet Oncol. 2014 Dec;15(13):1513-20.

11 Tiberio D, Franz DN, Phillips JR. Regression of a cardiac rhabdomyoma in a patient receiving everolimus. Pediatrics. 2011 May;127(5):e1335-7.

12 Breathnach C, Pears J, Franklin O, Webb D, McMahon CJ. Rapid regression of left ventricular outflow tract rhabdomyoma after sirolimus therapy. Pediatrics. 2014 Oct;134(4):e1199-202.

13 Chang JS, Chiou PY, Yao SH, Chou IC, Lin CY. Regression of Neonatal Cardiac Rhabdomyoma in Two Months Through Low-Dose Everolimus Therapy: A Report of Three Cases. Pediatr Cardiol. 2017 Oct;38(7):1478-84.

14 Weiland MD, Bonello K, Hill KD. Rapid regression of large cardiac rhabdomyomas in neonates after sirolimus therapy. Cardiol Young. 2018 Mar;28(3):485-9.

15 Roach ES, Gomez MR, Northrup H. Tuberous Sclerosis Consensus Conference: revised clinical diagnostic criteria. J Child Neurol. 2008;23:1238-9.
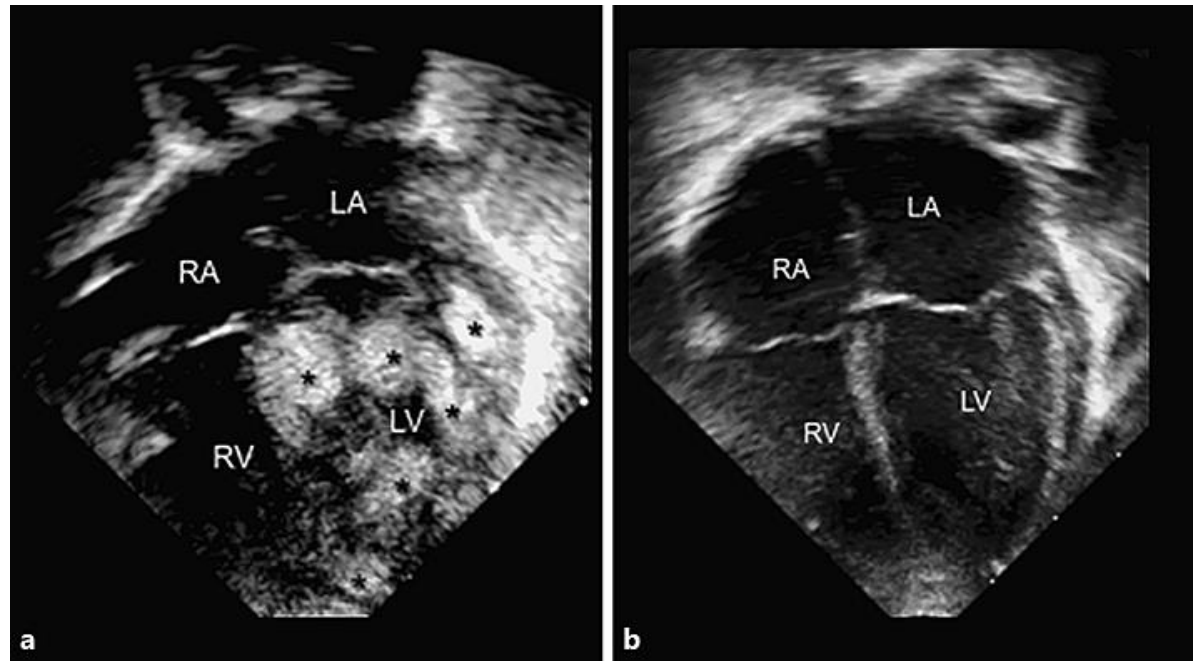

Fig. 1. A complete response to sirolimus therapy. a At baseline echo evaluation, patient 1 had at least 6 evident lesions involving left ventricle walls and the interventricular septum (shown with *). b After 1.9 months, a complete response was achieved. LV, left ventricle; RV, right ventricle; LA, left atrium; RA, right atrium. 


\section{Case Reports in Oncology}

\begin{tabular}{l|l}
\hline Case Rep Oncol 2018;11:425-430 \\
\hline DOI: 10.1159/000490662 & $\begin{array}{l}\text { (c) 2018 The Author(s). Published by S. Karger AG, Basel } \\
\text { www.karger.com/cro }\end{array}$ \\
\hline
\end{tabular}

Lucchesi et al.: Sirolimus in Infants with Multiple CRs Associated with TSC
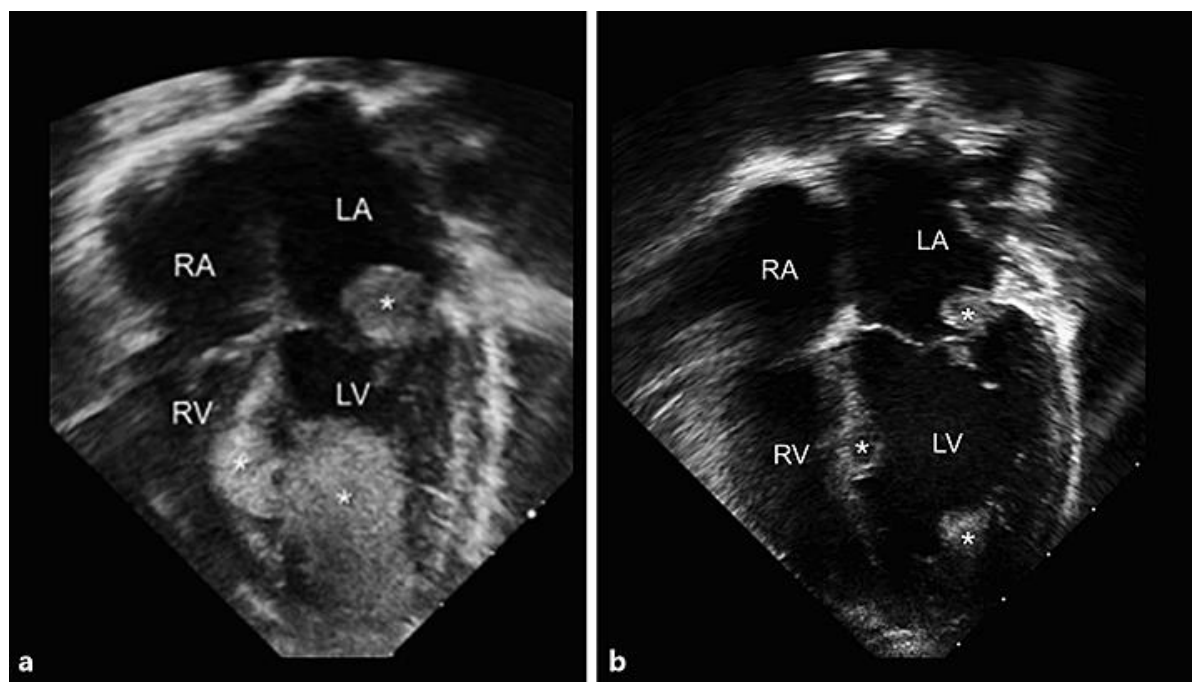

Fig. 2. A partial response to sirolimus therapy. a At baseline echo evaluation, patient 3 had at least 3 evident lesions (shown with *). Two of these lesions were in critical points: on the left atrioventricular valve, and in the left ventricle with filling of part of the ventricular chamber. $\mathbf{b}$ After 4.7 months, a partial response with tumor debulking greater than $50 \%$ was achieved. LV, left ventricle; RV, right ventricle; LA, left atrium; RA, right atrium.

Table 1. Clinical features of individual patients regarding tuberous sclerosis

\begin{tabular}{llllllllll}
\hline Patient & $\begin{array}{l}\text { Gene } \\
\text { mutations }\end{array}$ & $\begin{array}{l}\text { Cardiac } \\
\text { rhabdomyomas }\end{array}$ & $\begin{array}{l}\text { Cardiac } \\
\text { disorders }\end{array}$ & SEGAs & \multicolumn{2}{l}{$\begin{array}{l}\text { Refractory ep- Renal } \\
\text { ilepsy } \\
\text { angiomyolipomas }\end{array}$} & $\begin{array}{l}\text { Renal } \\
\text { disorders }\end{array}$ & $\begin{array}{l}\text { Retinal hamarto- Optical disor- Skin fi- } \\
\text { mas } \\
\text { broids }\end{array}$ \\
\hline 1 & NA & $\mathrm{P}$ & - & $\mathrm{P}$ & - & - & - & - & - \\
2 & TSC2 & $\mathrm{P}$ & - & $\mathrm{P}$ & $\mathrm{P}$ & - & - & $\mathrm{P}$ & - \\
3 & TSC2 & $\mathrm{P}$ & $\mathrm{P}$ & $\mathrm{P}$ & $\mathrm{P}$ & - & - & $\mathrm{P}$ & $\mathrm{P}$ \\
\hline
\end{tabular}

P, present; NA, not available; TSC2, tuberous sclerosis complex 2 gene. 